University of South Carolina

Scholar Commons

$6-30-2008$

\title{
Manipulating the Cavity of a Porous Material Changes the Photoreactivity of Included Guests
}

\author{
Mahender B. Dewal \\ University of South Carolina - Columbia \\ Yuewen Xu \\ University of South Carolina - Columbia \\ Jun Yang \\ University of South Carolina - Columbia \\ Fiaz Mohammed \\ University of South Carolina - Columbia \\ Mark D. Smith \\ University of South Carolina - Columbia, mdsmith3@mailbox.sc.edu
}

See next page for additional authors

Follow this and additional works at: https://scholarcommons.sc.edu/chem_facpub

Part of the Chemistry Commons

\section{Publication Info \\ Published in Chemical Communications, Volume 33, 2008, pages 3909-3911. \\ (c) Chemical Communications 2008, Royal Society of Chemistry.}

This Article is brought to you by the Chemistry and Biochemistry, Department of at Scholar Commons. It has been accepted for inclusion in Faculty Publications by an authorized administrator of Scholar Commons. For more information, please contact digres@mailbox.sc.edu. 


\section{Author(s)}

Mahender B. Dewal, Yuewen Xu, Jun Yang, Fiaz Mohammed, Mark D. Smith, and Linda S. Shimizu 


\title{
Manipulating the cavity of a porous material changes the photoreactivity of included guests $\dagger$
}

\author{
Mahender B. Dewal, Yuewen Xu, Jun Yang, Fiaz Mohammed, Mark D. Smith and \\ Linda S. Shimizu*
}

Received (in Austin, TX, USA) 9th April 2008, Accepted 7th May 2008

First published as an Advance Article on the web 30th June 2008

DOI: $10.1039 / \mathbf{b 8 0 5 8 9 5 d}$

\begin{abstract}
Changing an ether to a ketone within the framework of a bisurea macrocycle has little effect on the supramolecular assembly of this building block into porous crystals but introduces a triplet sensitizer into the framework that dramatically alters the photochemical reactions of included guests.
\end{abstract}

Supramolecular assembly deftly and efficiently creates materials with interesting structures and properties from small molecule building blocks. Some supramolecular assemblies, as well as more traditional porous materials and crystals, can be used as templates or vessels to promote chemical reactions with high regio- and stereoselectivity. ${ }^{1}$ It is not yet possible to predict how systematic changes in these nanoreactors influence the reactants. In this paper, we examine how a change in the framework of a self-assembling macrocycle influences the UVabsorption of the macrocycle and subsequently the reaction environment of the cavity.

We have previously reported bis-urea 1 synthesized from a phenylether spacer that assembled into columnar structures that pack against each other to give porous crystals. ${ }^{2,3}$ We now report a similar macrocycle $\mathbf{2}$ that is synthesized from a benzophenone spacer and also forms porous crystals. The two macrocycles differ in their linking groups (ether 1 versus ketone 2). The homogeneous channels of the two systems have comparable diameters by gas adsorption. They absorb a similar series of guests. Despite these similarities, the new benzophenone framework of host $\mathbf{2}$ facilitates different photochemical reactions within its nanochannels. Host $\mathbf{1}$ induces the $[2+2]$-photocycloaddition of $\alpha, \beta$-unsaturated ketones (Fig. 1), whereas host $\mathbf{2}$ is ineffective in facilitating this photocycloaddition. Conversely, only host $\mathbf{2}$ induces a rapid photoisomerization of trans- $\beta$-methylstyrene to the less stable cis-isomer (II), which is a reaction that does not proceed within host $\mathbf{1}$.

Macrocycle 1 self-assembled into columnar structures via urea-urea hydrogen bonds and aryl-stacking interactions forming crystals that display permanent porosity. ${ }^{3}$ These crystals reversibly bound guests with matched shapes and sizes and facilitated

Department of Chemistry and Biochemistry, University of South Carolina, Columbia, South Carolina, USA. E-mail:

shimizul@mail.chem.sc.edu; Fax: +1803-777-9521; Tel: +1803777-2066

$\dagger$ Electronic supplementary information (ESI) available: Experimental details including the synthesis and characterization of host $\mathbf{2}$ and crystallographic analysis. CCDC reference numbers 684399-684400. For ESI and crystallographic data in CIF or other electronic format see DOI: $10.1039 / \mathrm{b} 805895 \mathrm{~d}$ $[2+2]$-photocycloadditions of enones. ${ }^{4}$ We synthesized benzophenone macrocycle $\mathbf{2}$ in which the ether oxygen of host $\mathbf{1}$ was replaced with a carbonyl group. Host $\mathbf{2}$ was synthesized in two steps from the dibromide and masked urea (triazinanone). ${ }^{5}$ Cyclization under basic conditions yielded the urea-protected macrocycle, which crystallized as a chloroform solvate (S.I. $\dagger$ ). Deprotection with diethanolamine followed by recrystallization of 2 from hot DMSO afforded crystals suitable for X-ray analysis. $\ddagger$

The crystal structure of $\mathbf{2}$ revealed the expected bis-urea structure (Fig. 2) that assembles into columnar structures similar to host $1,{ }^{3}$ highlighting the predictability of this assembly motif. The macrocycles display strong urea-urea hydrogen bonds (Fig. 3) that extend along both sides of the tube with $\mathrm{H} \cdots \mathrm{O}$ distances from 2.17 to $2.30 \AA$. The individual monomers are also held together by edge to face aryl-stacking interactions. The sizeable channel of the assembly was filled with DMSO guests in a $1: 1$ (macrocycle : DMSO) ratio.

Heating removed the DMSO guest from the crystals, forming a host that maintains permanent porosity. The porosity of the empty host 2 was established by gas absorption using $\mathrm{CO}_{2}$ at $273 \mathrm{~K}$. The evacuated crystals displayed a type 1 gas adsorption isotherm (Fig. 4A), consistent with a microporous material. ${ }^{6}$ The Brunauer-Emmett-Teller method was applied to the isotherm at $P / P_{0}$ between 0.012 and 0.028 and the calculated surface area of $320 \mathrm{~m}^{2} \mathrm{~g}^{-1}$, comparable to the original framework $\mathbf{1}$

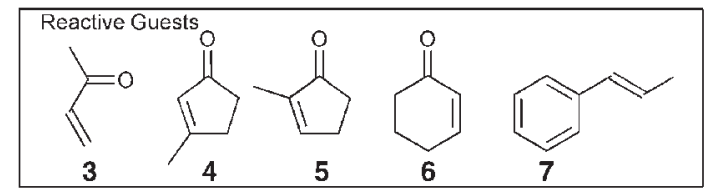

(1)<smiles>[R]C1=C(C)C(C)=CC1=O</smiles>
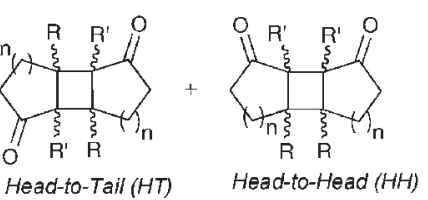

Head-to-Tail $(H T)$ Head-to-Head $(H H)$

$4 \mathrm{n}=1, \mathrm{R}=\mathrm{CH}_{3}, \mathrm{R}^{\prime}=\mathrm{H}$

$5 n=1, R=H, R^{\prime}=\mathrm{CH}_{3}$

$6 \mathrm{n}=2, \mathrm{R}=\mathrm{H}, \mathrm{R}^{\prime}=\mathrm{H}$

(II)

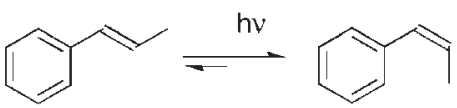

Fig. 1 The characteristics of these porous nanoreactors were probed using reactive guests (3-7) in two photochemical reactions: [2+2]photoadditions (I) where $\mathrm{R}, \mathrm{R}^{\prime}$ and $n$ depend on the identity of the starting cyclic enone and cis-trans photoisomerization (II) of styrene 7. 


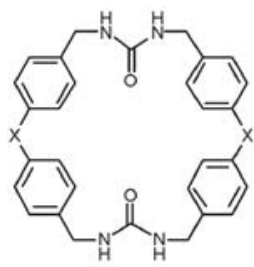

$1: X=0$
$2: X=C=0$

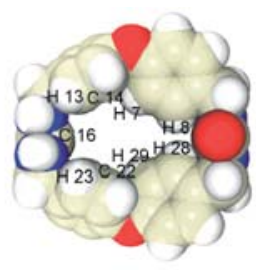

1

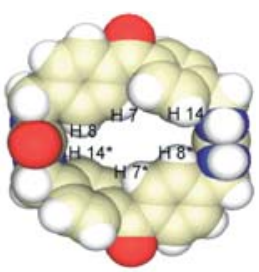

2
Fig. 2 Comparison of the cavities of two bis-urea macrocycles from $\mathrm{X}$-ray crystal structures. The dimensions of the channel between the van der Waals surfaces of the pore defining atoms (host 1: C16-H8 $\times$ $\mathrm{H} 7-\mathrm{H} 23=4.8 \times 3.8 \AA$, host $2: \mathrm{H} 8-\mathrm{H} 8 * \times \mathrm{H} 7-\mathrm{H} 7 *=3.7 \AA \times 2.7 \AA$ ).

$\left.\left(316 \mathrm{~m}^{2} \mathrm{~g}^{-1}\right)\right)^{3,7}$ This corresponds to a total pore volume of 0.059 $\mathrm{cm}^{3} \mathrm{~g}^{-1}$ for pores smaller than $6.9 \AA$ in diameter, which was similar to the values for host $\mathbf{1}$.

The reversible binding of guests was followed by several methods including powder X-ray diffraction (PXRD) and TGA (S.I. $\dagger$ ). Crystals of synthesized 2.DMSO were ground to a powder and examined by PXRD (Fig. 4B). The observed PXRD pattern closely matched simulated patterns based on the single-crystal structure (S.I. $\dagger$ ), indicating that the bulk powder retains a structure similar to that of the single crystal. Subsequent heating to $160{ }^{\circ} \mathrm{C}$ facilitated the removal of the included DMSO guest forming empty host $\mathbf{2}$. The empty host was highly crystalline by PXRD (Fig. 4B middle). Exposure of the empty host $\mathbf{2}$ powder to guest vapour resulted in reabsorption of the guests to reform host 2.DMSO, providing further evidence of the reversible nature of the absorption/desorption process. Both hosts absorbed small molecule solvents such as EtOAc, THF, and $\mathrm{AcOH}$ in identical host : guest ratios (S.I. $\dagger$ ). Larger reactants 3-7 were also absorbed by both hosts.

Although they have many similarities, the two hosts exhibit markedly different UV-absorbance spectra in DMSO (Fig. 5). Host 1 has no significant absorbance in the 320-380 nm range, which is important for [2+2]-cycloadditions of enones. In comparison, the benzophenone host $\mathbf{2}$ has a strong absorbance in this region with a $\lambda_{\max }$ at $339 \mathrm{~nm}$, similar to what is observed for 2-cyclohexenone $\left(\lambda_{\max }=335 \mathrm{~nm}\right)$.

Previous work demonstrated that enones 4-6 underwent facile $[2+2]$-cycloaddition reactions to yield the exo head-totail (HT) photodimers as the major product in high conversion (Table 1). ${ }^{4}$ The new solid inclusion crystals (host $\mathbf{2}$-enone) were UV-irradiated using a $450 \mathrm{~W}$ Hannovia high pressure mercury
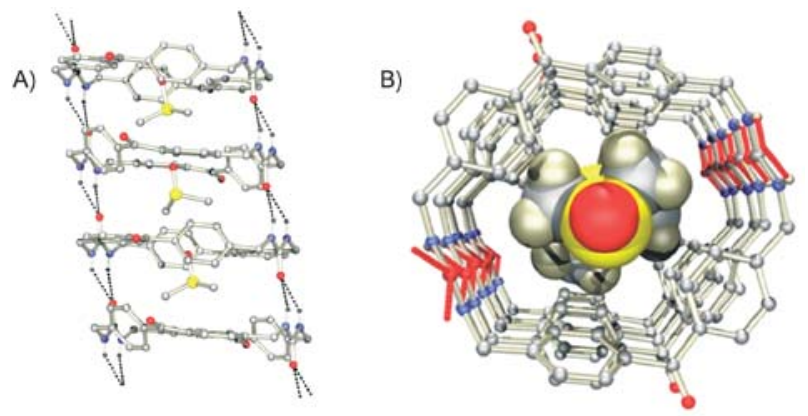

Fig. 3 Views from the crystal structure of host 2.DMSO. (A) View along a single column that contains a channel filled with DMSO guests. (B) Top view of column.

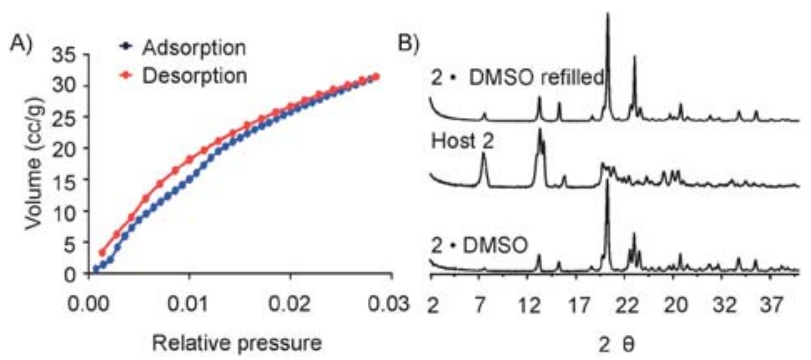

Fig. 4 (A) Carbon dioxide adsorption isotherms at $273 \mathrm{~K}$ for empty host 2. (B) Following the reversible binding by PXRD: 2.DMSO (bottom), empty host $\mathbf{2}$ (middle), and refilled 2.DMSO (top).

vapour lamp at $\sim 30{ }^{\circ} \mathrm{C}$ for $24 \mathrm{~h}$. Next, each of the host-guest complexes was directly dissolved in $d_{6}$-DMSO and monitored by ${ }^{1} \mathrm{H}$ NMR spectrometry. Only peaks that corresponded to the host macrocycle $\mathbf{2}$ and the starting enones were observed. These results are in stark contrast to the selective $[2+2]-$ cycloadditions facilitated by host $\mathbf{1}$.

How is one to explain this drastic difference in observed reactivity? Both hosts load the enones with high binding ratios (2.5: 1 for host $\mathbf{1 . 4} v s .2: 1$ for host $\mathbf{2 . 4}$ ), yet no reaction is observed within the second host. We attribute these differences to the UV-absorption characteristics of the two hosts. Host 1 does not have any significant absorbance in the wavelength ranging from 300 to $450 \mathrm{~nm}$, where most enones have strong absorption bands. Therefore, within host 1 these enones undergo the normal $[2+2]$-cycloaddition; however, host $\mathbf{2}$ displays a strong absorption in this range. Literature studies with 2-cyclopentenone in solution suggest that benzophenone transfers energy to the enone but that this triplet excited state is not conducive for the photoreaction. ${ }^{8}$

We next investigated both host $\mathbf{1}$ and host $\mathbf{2}$ as confined environments for the cis-trans photoisomerization of trans- $\beta$ methylstyrene 7 (Fig. 2, reaction II), which is a process known to require a triplet sensitizer. ${ }^{9}$ Can the covalent sensitizer of host 2 transfer energy to included guests? There are examples of sensitized photoreactions within zeolites loaded with benzophenone or in cases where acetophenone or benzophenone is covalently attached to small receptors. ${ }^{10}$

Styrene $7(\sim 4.3 \AA \times 7.7 \AA)$ was absorbed by both hosts through vapour loading to give stable inclusion complexes after $24 \mathrm{~h}$, which display similar host : guest ratios (host $\mathbf{1 . 7}$ (2.7 : 1 host : guest), host $2 \cdot 7$ (2.5: 1 host : guest)). Prolonged exposure to the styrene 7 vapour $(72 \mathrm{~h})$ did not alter the

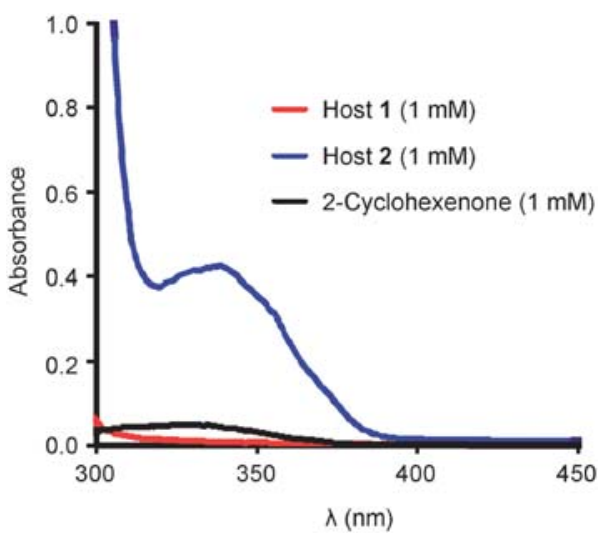

Fig. 5 UV absorbance of macrocycles $\mathbf{1}$ and $\mathbf{2}$ in DMSO. 
Table 1 Comparison of $[2+2]$-cycloadditions of $\alpha, \beta$-unsaturated ketones (3-6) and photoisomerization of trans- $\beta$-methylstyrene (7) in the presence of host $\mathbf{1}$ and host $\mathbf{2}$

\begin{tabular}{|c|c|c|c|c|}
\hline \multirow{2}{*}{\multicolumn{2}{|c|}{ reactant }} & \multicolumn{2}{|c|}{ Host 1} & \multirow{2}{*}{$\begin{array}{c}\text { Host } 2 \\
\text { conversion } \\
(24 \mathrm{~h})\end{array}$} \\
\hline & & $\begin{array}{c}\text { conversion } \\
(24 \mathrm{~h})\end{array}$ & $\begin{array}{c}\text { selectivity } \\
(\mathrm{HT})\end{array}$ & \\
\hline $\begin{array}{c}\text { Reaction } \\
\text { (I) }\end{array}$ & $\left\{\begin{array}{l}3 \\
4 \\
5 \\
6\end{array}\right.$ & $\begin{array}{l}0 \% \\
80 \% \\
96 \% \\
100 \% \\
\end{array}$ & $\begin{array}{l}- \\
98 \% \\
80 \% \\
96 \%\end{array}$ & $\begin{array}{l}0 \% \\
0 \% \\
0 \% \\
0 \% \\
\end{array}$ \\
\hline Reaction & reactant & $\begin{array}{c}\text { Host } 1 \\
t \quad \operatorname{cis}(24 \mathrm{~h})\end{array}$ & $\begin{array}{r}\text { no Host } \\
\text { cis }(24 \mathrm{~h})\end{array}$ & $\begin{array}{c}\text { Host } 2 \\
\text { cis (30 min) }\end{array}$ \\
\hline (II) & 7 & $0 \%$ & $<5 \%$ & $59 \%$ \\
\hline
\end{tabular}

binding ratios. The inclusion complex $\mathbf{2 . 7}(25 \mathrm{mg})$ was irradiated using a $450 \mathrm{~W}$ Hannovia high pressure mercury vapour lamp at $\sim 30{ }^{\circ} \mathrm{C}$ for $10 \mathrm{~min}$ to $24 \mathrm{~h}$. The reaction progress was followed by two methods: (A) direct dissolution of a sample in $d_{6}$-DMSO and integration of the proton NMR spectra; and (B) removal of guests from the porous framework by washing the crystals with $\mathrm{CH}_{2} \mathrm{Cl}_{2}$ and analysis by $\mathrm{GC} / \mathrm{MS}$. In the latter case, the host was recovered by filtration and reused.

After $30 \mathrm{~min}$ of UV irradiation, a rapid photoisomerization was observed in the host $\mathbf{2} \cdot \mathbf{7}$ complex yielding $59 \%$ conversion to the cis-isomer. Further UV-irradiation for 2 or $24 \mathrm{~h}$ yielded identical trans : cis ratios, indicating that this is the photostationary state within the crystals under broad band irradiation. In contrast, neat, degassed trans- $\beta$-methylstyrene $(25 \mathrm{mg})$ shows little photoisomerization under similar UV-irradiation, displaying $<5 \%$ cis after $24 \mathrm{~h}$. Literature reports show UV-irradiation $\left(366 \mathrm{~nm}, 26^{\circ} \mathrm{C}\right.$ ) of trans- $\beta$-methylstyrene with benzophenone sensitizer in benzene solution gave a comparable percentage of cis- $\beta$-methylstyrene $(63 \%)$ at the photostationary state $(3 \mathrm{~h}){ }^{9}$

To further test whether the photosensitizer was responsible for this photoisomerization, the inclusion complex $\mathbf{1 . 7}$ was subjected to UV-irradiation for $30 \mathrm{~min}$ to $24 \mathrm{~h}$. Host $\mathbf{1}$ is of similar size and shape yet contains no triplet sensitizer to facilitate the cis-trans photoisomerization. Indeed, no cisisomer was detectable by proton NMR after $24 \mathrm{~h}$ of UVirradiation. These results suggest that it is the benzophenone within the framework that is important for the rapid isomerization of $\mathbf{7}$ within host $\mathbf{2}$. Furthermore, these results indicate that the benzophenone within the covalent framework of macrocycle $\mathbf{2}$ is able to act as a triplet sensitizer for this reaction, transferring energy to the included styrene guest.

We reported a new bis-urea macrocycle that self-assembles predictably into columnar structures containing DMSO guests. The guests can be removed from these crystals by heating to form a host that maintains permanent porosity. This new macrocycle is similar in dimensions to a previously reported phenylether derivative and absorbs similar guests with nearly the same host : guest ratios. Although similar in size, the two hosts promote different photochemical reactivity for absorbed guests. Host 1 enables the facile $[2+2]$-cycloaddition to yield HT photodimers in high selectivity and conversion. In contrast, host $\mathbf{2}$ facilitated the triplet sensitized cis-trans photoisomerization of trans- $\beta$-methylstyrene. These results show that small changes within the framework of porous materials can greatly influence the reactions that occur within these channels. The most intriguing property of porous host $\mathbf{2}$ arises from the benzophenone anchored in the framework. We are now investigating the scope of host $\mathbf{2}$ to facilitate other photochemical reactions that may proceed selectively in the presence of a triplet sensitizer. We will also investigate if host $\mathbf{2}$, with its broad UV-absorbance, can induce photoreactions at longer wavelengths than typically required.

The authors gratefully acknowledge support in part for this work from the NSF (CHE-071817), from the Petroleum Research Fund (44682), and from a grant from the University of South Carolina, Office of Research and Health Sciences.

\section{Notes and references}

$\ddagger$ Crystallographic data for $2: \mathrm{C}_{34} \mathrm{H}_{34} \mathrm{~N}_{4} \mathrm{O}_{5} \mathrm{~S}, M=610.71$. Colourless block crystal, $0.16 \times 0.10 \times 0.08 \mathrm{~mm}^{3}, T=150 \mathrm{~K}$. Monoclinic, space group $P 2_{1} / c, a=9.4680(6), b=23.055(2), c=13.3023(9) \AA$, $\beta=92.765(2)^{\circ}, U=2900.3(3) \AA^{3}, Z=4, D_{\mathrm{c}}=1.399 \mathrm{Mg} \mathrm{m}^{-3}$, $F(000)=1288$. Bruker SMART APEX CCD-based diffractometer system, $\lambda=0.71073 \AA(\mathrm{Mo}-\mathrm{K} \alpha), \theta_{\max }=22.54^{\circ}, 21351$ reflections measured, 3813 unique, 2456 with $I>2 \sigma(I), R_{\mathrm{int}}=0.0801$. Final $R$-values: $R 1(F, I>2 \sigma(I))=0.0675 ; w R 2\left(F^{2}\right.$, all data $)=0.1722$.

1 D. M. Vriezema, M. C. Aragones, J. A. A. W. Elemans, J. J. L. M. Cornelissen, A. E. Rowan and R. J. M. Nolte, Chem. Rev., 2005, 105, 1445; J. S. Seo, D. Whang, H. Lee, S. I. Jun, J. Oh, Y. J. Jeon and K. Kim, Nature, 2000, 404, 982; C. D. Wu, A. Hu, L. Shang and W. Lin, J. Am. Chem. Soc., 2005, 127, 8940; A. Corma and H. Garcia, Chem. Commun., 2004, 1443; D. Fiedler, D. H. Leung, R. G. Bergman and K. N. Raymond, Acc. Chem. Res., 2005, 38, 351; M. Conn and J. Rebek, Jr, Acc. Chem. Res., 1997, 97, 1647; B. W. Purse and J. Rebek, Jr, Proc. Natl. Acad. Sci. U. S. A., 2005, 102, 10777; A. Natarajan, L. S. Kanumalle, S. Jockusch, C. L. D. Gibb, B. C. Gibb, N. J. Turro and V. Ramamurthy, J. Am. Chem. Soc., 2007, 129, 4132; D. B. Varshney, X. Gao, T. Friscic and L. R. MacGillivray, Angew. Chem., Int. Ed., 2006, 45, 646; D. N. Dybstev, A. L. Nuzhdin, H. Chun, K. P. Bryliakov, E. P. Talsi, V. P. Fedin and K. Kim, Angew. Chem., Int. Ed., 2006, 45, 916; T. Arai, H. Sakuragi and K. Tokumaru, Bull. Chem. Soc. Jpn., 1982, 55, 2204; R. A. Caldwell, G. W. Sovocool and R. J. Peresie, J. Am. Chem. Soc., 1973, 95, 1496.

2 L. S. Shimizu, A. D. Hughes, M. D. Smith, M. J. Davis, P. Zhang, H.-C. zur Loye and K. D. Shimizu, J. Am. Chem. Soc., 2003, 125, 14972.

3 M. B. Dewal, M. W. Lufaso, A. D. Hughes, S. A. Samuel, P. Pellechia and L. S. Shimizu, Chem. Mater., 2006, 18, 4855.

4 J. Yang, M. B. Dewal and L. S. Shimizu, J. Am. Chem. Soc., 2006, 128, 8122; J. Yang, M. B. Dewal, S. Profeta, Y. Li, M. D. Smith and L. S. Shimizu, J. Am. Chem. Soc., 2008, 130, 612.

5 A. R. Mitchell, P. F. Pagoria, C. L. Coon, E. S. Jessop, J. F. Pococ, C. M. Tarver, R. D. Breithaupt and G. L. Moody, Propellants, Explos., Pyrotech., 1994, 19, 232.

6 K. S. W. Sing, D. H. Everett, R. A. W. Haul, L. Moscou, R. A. Pierotti, J. Rouquerol and T. Siemieniewska, Pure Appl. Chem., 1985, 57, 603.

7 T. J. Barton, L. M. Bull, W. G. Klemperer, D. A. Loy, B. McEnaney, M. Misono, P. A. Monson, G. Pez, G. W. Scherer, J. C. Varuli and O. M. Yaghi, Chem. Mater., 1999, 11, 2633; J. C. Groen, L. Peffer and J. A. Perez-Ramirez, Microporous Mesoporous Mater., 2003, 12, 56.

8 P. de Mayo, J.-P. Pete and M. Tchir, J. Am. Chem. Soc., 1967, 89, 5712.

9 T. Arai, H. Sakuragi and K. Tokumaru, Bull. Chem. Soc. Jpn., 1982, 55, 2204; M. G. Rockley and K. Salisbury, J. Chem. Soc., Perkin Trans. 2, 1973, 1582.

10 A. Corma and G. Hermenegildo, Chem. Commun., 2004, 1443-1459; M. V. Baldovi, A. Corma, H. Garcia and V. Marti, Tetrahedron Lett., 1994, 35, 9447; K. Kokubo, K. Kitasaka and T. Oshima, Org. Lett., 2006, 8, 1597; M. V. Baldovi, F. L. Cozens, V. Fornes, H. Garcia and J. C. Scaiano, Chem. Mater., 1996, 8, 152; H. Nishiguchi, S. Okamoto and M. Nishimura, Res. Chem. Intermed., 1998, 24, 849. 